Building Effective Risk Communication and Crisis Communication Programs by Implementing the Theory of Constraints Model

Gili Shenbar, EMB, ${ }^{1}$ David Gidron, $M A,{ }^{2}$ Kobi Peleg, $P b D, M P H^{3}$

1. Gertner Institute for Epidemiology and Health Policy Research; Academic Coordinator for the Master's Degree in Disaster Management at Tel Aviv University, Tel Aviv, Israel

2. Gertner Institute for Epidemiology and Health Policy Research, Israel

3. Director, Israel National Center for Trauma and Emergency Medicine, Gertner Institute for Epidemiology and Health Policy Research, and Head of the Multi-disciplinary Program for Emergency and Disaster Management, School of Public Health, Tel-Aviv University, Tel Aviv, Israel

The aim of this paper is to propose a method for Risk and Crisis Communication (RCCC), and to formulate ways of applying it in order to obtain a better general response on the part of the authorities and the public during a disaster. The implementation of the Theory of Constraints (TOC) model is well known in the business management arena. The TOC is said to be "portable" over a wide range of problems that previously were intractable. The importance the bottlenecks in the disaster management process was underlined in this model. This process has two different bottlenecks. The bottleneck at the preparedness phase is a result of the public's lack of attentiveness, and during the disaster, it is the ability to produce and deliver the information to the public. Being aware of the constraints (bottlenecks) in the process allows researchers to minimize or even solve the problem using existing tools. Implementing the TOC model in RCCC has a major contribution in reducing the number of losses of human life, disability and property.

Keywords: communication; crisis communication; risk communication; Theory of Constraints Prehosp Disaster Med

Improving Risk Communication for Radiological/Nuclear Threats: Recent Research and New Initiatives

Steven M. Becker, $P b D$

Associate Professor of Public Health, and Vice Chair, Department of Environmental Health Sciences, The University of Alabama at Birmingham, Birmingham, Alabama USA

Reducing morbidity and mortality during a radiological/nuclear terrorism event depends heavily on effective crisis and emergency risk communication. Thus, preparedness and response agencies, policymakers, researchers, and others are devoting increasing attention to communication and information issues. Recent research and new initiatives related to radiological/nuclear risk communication will be discussed. Studies involving clinicians, health department personnel, first responders, and the general public are considered, as are key governmental and non-governmental initiatives. Future challenges in improving risk communication for radiological/nuclear terrorism events will be discussed.

Keywords: communication; improvement; initiative; nuclear; radiological; risk communication; terrorism

Prehosp Disaster Med
Safety Function Action: International Applications of a Disaster Health Framework for Citizens and Disaster Responders

James Shultz, $M S, P b D,{ }^{1}$ Andrea Allen, $P b D, 2$

Zelde Espinel, $M D, M A, M P H^{1}$

1. Center for Disaster \& Extreme Event Preparedness (DEEP Center), University of Miami Miller School of Medicine, Miami, Florida USA

2. Barry University, Miami, Florida USA

Introduction: Safety Function Action (SFA) is a disaster health training program for a broad spectrum of disaster responders and the general public. Disaster health is defined as maximal safety, optimal function, and effective action in response to emergencies, disasters, humanitarian crises, and extreme events. The $S F A$ integrates precepts from public health, public safety, disaster behavioral health, and medical preparedness.

With $S F A$, a single, six-strategy framework is flexibly applied to support disaster responders and disaster survivors. To achieve maximal safety, strategies are safeguard and sustain. To achieve optimal function, strategies are comfort and connect. To achieve effective action, strategies are advise and activate.

Methods: The $S F A$ has been trained extensively in Florida and throughout the US and Canada. In 2009, 861 Florida responders were trained as "facilitators," tasked with bringing $S F A$ from the classroom to their respective work teams. Facilitators were supported by a team of DEEP Centerbased "coaches." Miami-Dade Schools crisis counselors, trained as SFA facilitators, have responded to school slayings and the H1N1 influenza pandemic during Fall 2009. Multi-day training of $S F A$ "trainers" was conducted in Vancouver, Canada; trainers now are imparting $S F A$ to "psychosocial" teams preparing for service in the 2010 Winter Olympics. During fall 2009, SFA is being trained to multi-disciplinary responder audiences in Halifax and Toronto, Canada. The $S F A$ training in Spanish will be conducted in Armenia, Colombia (site of a massive 1999 earthquake). Colombia's Ministry of Health plans twin applications of $S F A$ : natural disaster responders/survivors and internally displaced populations.

The $S F A$ is being extended to general public applications and is now accessible online. The SFA Family Disaster Plan is being disseminated to responders and citizens.

Conclusions: The $S F A$ provides a widely applicable framework for promoting disaster health among responders and citizens, combining psychosocial components with health and safety.

Keywords: disaster; health; psychosocial; safety; Safety Function Action; training

Prebosp Disaster Med

\section{Risk Communication}

\section{LTC Ariella Ben Avraham}

Home Front Command, Israel Defense Forces, Israel

Conflicts such as the Gulf War (1991), the Second Lebanon War (2006), the last operation in Gaza (2009), and the worldwide terrorist attacks have created a challenging situation for the Home Front Command given that the battlefield has shifted to the civilian population. The civil- 
ian population is composed of diverse social groups with different, sometimes conflicting interests, unlike armed organizations and/or defense forces.

The civilian population, naturally, is not prepared to cope with such threats and its resilience and ability to cope depends mainly on the national response in raising the awareness and providing the civilian population with constant information. This is a challenge that the Home Front Command is facing.

One of the major tools in facing the challenge and preparing the civilian population to cope with emergencies is the risk communication program. "Risk communication" has a unique meaning in the Home Front Command. For most of the world, the term risk communication means information exchange, training, information management, etc. In the Home Front Command risk communication is referred to as more of a process rather than an act. It is an ongoing process which is aimed to motivate, educate, stimulate, and induce the public to lifesaving behaviors or mechanisms in case of an emergency. It achieves this goal by providing the civilian population with information, training, guidance, and support, year-round.

The concept of risk communication is based on the necessary and vital association between the actions of providing information, training, guidance, and support and the effectiveness and efficiency of the behavior of the public in daily life and in emergency situations--behavior that has the power to save lives.

This concept offers tools based on the theoretical and practical knowledge of the Home Front Command in providing the public with information and guidance with the best results.

There are many questions associated with "information and guidance", such as: should one provide with all the information and when? What should one say? How? When? What are the features of effective and efficient information? What are the most central information channels? Does one react to the source of the threat alone or should he or she take in consideration the public and the individual reaction?

This presentation will address the characteristics of the Israeli social environment in implementing/conducting risk communication to the public; the Isracli society; the media; the emergency organizations; the enemy; the principals and methods in conducting effective risk communication in everyday and in emergency; and the process of risk communication from the young to the old.

Keywords: civilian population; Home Front Command; information; Israel; risk communication Prebosp Disaster Med

\section{Management of Non-Conventional Events}

Planning and Preparedness for Hazardous Substance

Releases in India

V. Kapil, ${ }^{1}$ H. Falk, ${ }^{1}$ P. Ruckart; ${ }^{1}$ A. Dewan, ${ }^{2}$ M. Orr; ${ }^{1}$

J. Madden ${ }^{1}$

1. Centers for Disease Control and Prevention, Atlanta, Georgia USA

2. Indian Council of Medical Research, New Dehli, India

Introduction: The Indo-US Collaboration on Environmental and Occupational Health and Injury Prevention and Control was established by the US Department of Health and Human Services/Centers for Disease Control and Prevention (HHS/CDC) and the Indian Ministry of Health and Family Welfare (MOHFW) in 2002 to promote collaborative research, training, and capacity building in various areas of environmental and occupational health including emergencies. A related bi-national agreement focusing on injury prevention and trauma system enhancement recently was developed and implemented. The agreements include joint efforts to enhance emergency preparedness and responses for accidental or disaster-related releases of hazardous substances. The history and evolution of this binational agreement will be discussed as a model for public health preparedness cooperation with low- and middleincome countries.

Methods: Under the auspices of this agreement, the CDC worked closely with partner agencies in India to conduct surveillance of hazardous substance releases in the State of Gujarat. This surveillance was modeled after the US Hazardous Substances Emergency Events Surveillance (HSEES) system that CDC utilizes in 14 states. Data from 2005-2007 were collected in India and entered into a secure Web-based application. Information collected for each event included the type of release, location and industry involved in the event, number of victims, hospitalizations, deaths, evacuations, and contributing factors for the event.

Results: Results for hazardous substance releases in Gujarat State will be presented and the Indian experience will be compared with relevant US data. Joint training programs for the acute management of hazardous substance exposures will be described and discussed.

Conclusions: Both India and the US face numerous common challenges in preparing for a variety of environmental emergencies and disasters resulting in mass casualties. Potential threats include chemical agents, biological or radioactive substance releases, and other similar events that may result in a large surge of patients to health care facilities. The findings from Gujarat have implications for preparedness and response planning for similar events in many low- and middle-income countries.

Keywords: capacity building; hazardous materials; India; lowincome country; preparedness

Prebosp Disaster Med 